\title{
Evaluation of reference genes for insect olfaction studies
}

\author{
Bonaventure Aman Omondi ${ }^{1,2+}$, Jose Manuel Latorre-Estivalis ${ }^{3{ }^{*}+}$, Ivana Helena Rocha Oliveira ${ }^{3}$, Rickard Ignell \\ and Marcelo Gustavo Lorenzo ${ }^{3}$
}

\begin{abstract}
Background: Quantitative reverse transcription PCR (qRT-PCR) is a robust and accessible method to assay gene expression and to infer gene regulation. Being a chain of procedures, this technique is subject to systematic error due to biological and technical limitations mainly set by the starting material and downstream procedures. Thus, rigorous data normalization is critical to grant reliability and repeatability of gene expression quantification by qRT-PCR. A number of 'housekeeping genes', involved in basic cellular functions, have been commonly used as internal controls for this normalization process. However, these genes could themselves be regulated and must therefore be tested a priori.

Methods: We evaluated eight potential reference genes for their stability as internal controls for RT-qPCR studies of olfactory gene expression in the antennae of Rhodnius prolixus, a Chagas disease vector. The set of genes included were: a-tubulin; $\beta$-actin; Glyceraldehyde-3-phosphate dehydrogenase; Eukaryotic initiation factor 1A; Glutathione-S-transferase; Serine protease; Succinate dehydrogenase; and Glucose-6-phosphate dehydrogenase. Five experimental conditions, including changes in age,developmental stage and feeding status were tested in both sexes.

Results: We show that the evaluation of candidate reference genes is necessary for each combination of sex, tissue and physiological condition analyzed in order to avoid inconsistent results and conclusions. Although, Normfinder and geNorm software yielded different results between males and females, five genes (SDH, Tub, GAPDH, Act and G6PDH) appeared in the first positions in all rankings obtained. By using gene expression data of a single olfactory coreceptor gene as an example, we demonstrated the extent of changes expected using different internal standards.

Conclusions: This work underlines the need for a rigorous selection of internal standards to grant the reliability of normalization processes in qRT-PCR studies. Furthermore, we show that particular physiological or developmental conditions require independent evaluation of a diverse set of potential reference genes.
\end{abstract}

Keywords: RT-qPCR, Reference genes, Normalization process, Olfaction and triatomines

\section{Background}

The kissing bug Rhodnius prolixus (Heteroptera; Reduviidae; Triatominae) is the second most important vector of Chagas disease, transmitting Trypanosoma cruzi to humans in Colombia and Venezuela [1-3]. This bug is considered a classical model for insect physiology and has been used extensively to study aspects of insect biology such as gut function [4,5], diuresis [6-10], neuropeptide production [11-14], and behaviour [15-17]. Moreover, $R$. prolixus has recently been suggested as a model to study the molecular bases of

\footnotetext{
* Correspondence: jose.estivalis@cpqrr.fiocruz.br

†Equal contributors

${ }^{3}$ Vector Behavior and Pathogen Interaction Group, Centro de Pesquisas René Rachou, FIOCRUZ, Belo Horizonte, Minas Gerais, Brazil

Full list of author information is available at the end of the article
}

insect sensory perception and behaviour [18]. Quantitative reverse transcription PCR (qRT-PCR) or RNA-Seq analyses can be used to study these processes. However, a proper analysis based on these methods requires adequate normalization procedures.

Quantitative reverse transcription PCR (qRT-PCR) is the most robust and accessible method to detect and quantify messenger RNA (mRNA) transcription levels associated with specific physiological conditions [19-22] or genetic manipulation, e.g. RNA interference [23-25]. The technique has also been used to validate RNA-Seq [26-28] and microarray results [29]. Quantitative reverse transcription PCR offers sensitivity, a large dynamic range, accurate quantification, and the possibility to measure 
expression levels in different samples for a number of target genes [21,30-32]. It also enables intensive replication and statistical analysis that is not possible with more expensive methods like RNA-Seq. However, qRT-PCR is subject to systematic error from biological and technical limitations set by: (i) use of samples with different quality and amount of starting material, which affects RNA extraction efficiency; (ii) inaccurate quantification of the extracted RNA; (iii) variability of the reverse transcription reaction efficiency; and (iv) highly subjective data analysis [20,21,30-33]. These limitations make the systematic normalization of gene expression data important to improve the fidelity and accuracy of qRT-PCR. For this, the expression levels of a target and a reference gene are simultaneously measured in a sample. Subsequently, any changes in target gene expression are expressed relative to those of the reference gene, a process named relative quantification. An alternative is to refer target gene expression to sample concentration, also called absolute quantification. The first is the ideal choice when one intends to compare the relative change in expression of a target gene under different physiological conditions. In contrast, absolute quantification is more adequate when the total number of copies of a gene is to be determined.

For relative quantification, an ideal reference gene should have minimal expression variability in the different tissues, cells or physiological states under study [20-22,30-38]. Intuitively, this may imply that genes like $\alpha$-tubulin, GAPDH or $\beta$-actin that are required for structural and basic cellular function (housekeeping genes) would be best suited for this purpose. However, stably expressed genes may not exist in practice [30,31]. In fact, some of the most common reference genes used to date have been shown to suffer significant regulation under specific experimental conditions, and are therefore inappropriate for normalization purposes [39-45]. For this reason, an ideal approach would be to test a set of potential reference genes in all experimental conditions to be studied and select the best-suited genes for each comparison $[19,30,31,33]$. Nevertheless, many gene expression studies use reference genes without previously validating expression stability $[21,46]$. In case the expression profile of the selected reference gene is altered between the experimental conditions being studied, this change would be transferred to the calculations made on the dataset, biasing the conclusions obtained [20-22,30-33]. For R. prolixus, the stability of several reference genes has already been tested in different tissues (anterior and posterior midgut, ovary, fat body, flight muscle and salivary glands) considering the effects of nutrition and trypanosome infection [38,47]. Nevertheless, further studies dealing with different tissues and experimental conditions in this species are required to avoid basing the choice of reference genes exclusively on previous studies.
Transcript levels are generally low in studies dealing with tissues expressing olfactory genes. Furthermore, changes in olfactory gene expression under different physiological conditions are often subtle and, therefore the normalization of expression data is a critical process. The olfactory system is crucial for insects, and it plays a fundamental role in host location by insect vectors [48-50]. qRT-PCR has been widely used for the functional characterization of many genes related to olfaction in different insects such as Drosophila [51], mosquitoes [52,53], moths [54,55], bees [56,57], and termites [58]. However, few studies have presented evidence of objective selection of reference genes for the tissues and conditions under study.

The present work analyzed the stability of the expression profiles of eight potential reference genes in the antennae of $R$. prolixus. These profiles were compared separately in both sexes for five different conditions involving changes in nutritional status, developmental stage and adult age.

\section{Methods}

Insects

Insects were obtained from the colony of intradomiciliary $R$. prolixus established in Centro de Pesquisas René Rachou (CPqRR) more than 20 years ago (donated by Dr. Carlos Ponce, Ministerio de Salud Pública, Honduras). Experimental insects were reared under controlled conditions at $26 \pm$ $1^{\circ} \mathrm{C}, 65 \pm 10.0 \%$ relative humidity, and a $12: 12 \mathrm{~h}$ light/dark illumination cycle provided by artificial lights (4 fluorescent lamps, cold white light, $6400 \mathrm{~K}, 40 \mathrm{~W}$ ). All tests were performed with $5^{\text {th }}$ instar larvae or adults, separately for both sexes. All ages subsequently described for treatments represent the number of days elapsed after insects underwent ecdysis to their current instar. The expression of reference gene candidates was analyzed in five different conditions: (i) 21 day-old unfed $5^{\text {th }}$ instar larvae; (ii) 21 day-old fed $5^{\text {th }}$ instar larvae; (iii) 1 day-old unfed adults; (iv) 21 day-old unfed adults; (v) 21 day-old fed adults. An artificial feeder was used five days before sample preparation to feed the corresponding insects with citrated rabbit blood (2.5\% buffered sodium citrate) provided by the Centro de Criação de Animais de Laboratório (CECAL) from Fundação Oswaldo Cruz (FIOCRUZ). Six samples of 60 antennae each (i.e., from 30 bugs) were analyzed for each of the five treatments.

\section{Candidate reference genes and primer design}

Eight candidate reference genes previously used for qRT-PCR normalization in triatomines $[38,47]$ and other insect species $[19,33,59,60]$ were selected: $\alpha$-tubulin $(T u b) ; \beta$-actin $(A c t)$; Glyceraldehyde-3-phosphate dehydrogenase (GAPDH); Eukaryotic initiation factor $1 \mathrm{~A}$ $(e I F-1 a)$; Glutathione-S-transferase (GST); Serine protease $(S p)$; Succinate dehydrogenase $(S D H)$; and Glucose-6phosphate dehydrogenase $(G 6 P D H)$. All of these genes were identified in the $R$. prolixus genome database 
(available in www.vectorbase.org/organisms/rhodniusprolixus) using a local tBLASTn algorithm [61] and orthologous sequences from UniProt Knowledgebase (details showed in Additional file 1: Table S1), except for $S p$ already identified in $R$. prolixus by Bedoya and Lowenberger (Sequence ID: B8QQQ1, submitted in April 2008 to EMBL/GenBank/DDBJ databases). Primers were designed using Primer3 4.0.0 (http://primer3.wi.mit.edu) [62]. The melting temperature was set at $60^{\circ} \mathrm{C}$ and the specificity for each primer was tested in silico using BLASTn [63] in the $R$. prolixus genome database. As much as possible, primers were designed to amplify a product between 100 to $200 \mathrm{bp}$, to flank or straddle an intron, proximate to the first exons at the 3 ' terminus of each gene, to promote amplification efficiency, and exclude amplification of genomic DNA. The primer pairs were tested for homo- and hetero-dimerisation using the Oligoanalyser online tool (Integrated DNA Technologies, Inc. IA, USA). The main characteristics of the designed primers are shown in Table 1.

\section{RNA extraction and CDNA synthesis}

Total RNA was extracted in $500 \mu \mathrm{L}$ of TRIzol $^{\circ}$ Reagent (Life Technologies, Carlsbad, CA, USA) from pools of 60 antennae according to the manufacturer's instructions. The extracted RNA was resuspended in $30 \mu \mathrm{L}$ of DEPC-treated water (Life Technologies). RNA concentration was determined using a Qubit ${ }^{\circ}$ 2.0 Fluorometer
(Life Technologies) and RNA integrity was analyzed by means of electrophoresis in 2\% agarose gels visualized after GelRed ${ }^{\mathrm{Tm}}$ staining (Biotium Inc, Hayward, CA, USA). Genomic DNA was eliminated using the RQ1 RNase-Free DNase kit (Promega, Fitchburg, WI, USA). All treated RNA $(11 \mu \mathrm{L})$ was immediately used to synthesize cDNA samples using the SuperScript III Reverse Transcriptase (Life Technologies) and a 1:1 mix of Random Hexamers and $10 \mu \mathrm{M}$ Oligo (dT) 20 primers in a final volume of $20 \mu \mathrm{L}$. The reverse transcription reactions were performed in a MasterCycler ${ }^{\circ}$ Gradient Thermal Cycler (Hauppauge, NY, USA) under the following conditions: $10 \mathrm{~min}$ at $25^{\circ} \mathrm{C} ; 60 \mathrm{~min}$ at $50^{\circ} \mathrm{C}$ and $15 \mathrm{~min}$ at $70^{\circ} \mathrm{C}$. Finally, cDNAs were stored at $-20^{\circ} \mathrm{C}$.

\section{Quantitative real-time PCR}

For qRT-PCR, $10 \mu \mathrm{L}$ of SYBR Green PCR Master Mix ${ }^{\circ}$ (Life Technologies) were used for reaction mixtures that also contained $1 \mu \mathrm{L}$ of 2 -fold diluted cDNA sample and $0.8 \mu \mathrm{L}$ of a $10 \mu \mathrm{M}$ primer solution in a final reaction volume of $20 \mu \mathrm{L}$. The reactions were performed in an ABI PRISM 7500 Sequence Detection System (Life Technologies) under the following conditions: $10 \mathrm{~min}$ at $95^{\circ} \mathrm{C}$, followed by 40 cycles of $15 \mathrm{~s}$ at $95^{\circ} \mathrm{C}, 20 \mathrm{~s}$ at $60^{\circ} \mathrm{C}$, and $30 \mathrm{~s}$ at $72^{\circ} \mathrm{C}$. After the amplification step, melting curve analyses $\left(\mathrm{HRM}\right.$ rate $\left.=0.5^{\circ} \mathrm{C}\right)$, and electrophoreses in $2 \%$ agarose gels visualized after GelRed $^{\text {Tn }}$ staining (Biotium Inc, Hayward, CA, USA) were performed with qRT-PCR

Table 1 Characteristics of the candidate reference genes and ionotropic receptor co-receptor primers

\begin{tabular}{|c|c|c|c|c|c|c|}
\hline Gene & Biological function & Primer sequence $\left(5^{\prime}\right.$ to $\left.3^{\prime}\right)$ & Amplicon length (bp) & Intron length (bp) & $\mathrm{R}^{2}$ & $E(\%)$ \\
\hline \multirow[t]{2}{*}{ Act } & \multirow[t]{2}{*}{ Cytoskeletal protein } & For- TGTCTCCCACACTGTACCCATCTA / & \multirow[t]{2}{*}{87} & \multirow[t]{2}{*}{338} & \multirow[t]{2}{*}{0.992} & \multirow[t]{2}{*}{$88.2 \%$} \\
\hline & & Rev- TCGGTAAGATCACGACCAGCCAA & & & & \\
\hline \multirow[t]{2}{*}{ elf-1a } & \multirow[t]{2}{*}{ Protein biosynthesis } & For- TTGGAGGCCATGTGCTTTGAT / & \multirow[t]{2}{*}{94} & \multirow[t]{2}{*}{183} & \multirow[t]{2}{*}{0.999} & \multirow[t]{2}{*}{$91,3 \%$} \\
\hline & & Rev-AGGTTTCTTGCTTCATCTGGAGT & & & & \\
\hline \multirow[t]{2}{*}{ GAPDH } & \multirow[t]{2}{*}{ Glycolytic protein } & For- GACTGGCATGGCATTCAGAGTT / & \multirow[t]{2}{*}{182} & \multirow[t]{2}{*}{1130} & \multirow[t]{2}{*}{0.992} & \multirow[t]{2}{*}{$102.5 \%$} \\
\hline & & Rev- CCCCATTAAAGTCCGATGACACC & & & & \\
\hline \multirow[t]{2}{*}{ GST } & \multirow[t]{2}{*}{ Metabolism } & For- TACCCATCATTTGGCGTGGACA / & \multirow[t]{2}{*}{177} & \multirow[t]{2}{*}{ Intron - Exon junction } & \multirow[t]{2}{*}{0.987} & \multirow[t]{2}{*}{$103.2 \%$} \\
\hline & & Rev- CAAACCCAATTGCCTCAGCGAT & & & & \\
\hline \multirow[t]{2}{*}{ G6PDH } & \multirow[t]{2}{*}{ Metabolism } & For- AGCCTGGAGAAGCGGTTTACGTTA / & \multirow[t]{2}{*}{162} & \multirow[t]{2}{*}{923} & \multirow[t]{2}{*}{0.998} & \multirow[t]{2}{*}{$96.5 \%$} \\
\hline & & Rev- GTGAGCCACAGAATACGTCGAGT & & & & \\
\hline \multirow[t]{2}{*}{ SDH } & \multirow[t]{2}{*}{ Metabolism } & For- TTGCCGGAGTAGATGTTACCAG / & \multirow[t]{2}{*}{147} & \multirow[t]{2}{*}{1592} & \multirow[t]{2}{*}{0.999} & \multirow[t]{2}{*}{ 104.8\% } \\
\hline & & Rev- CAGCTGCATAAAGTCCTTCCAC & & & & \\
\hline$S p$ & Metabolism & For- AGGGACCATCTTTGACTGCTCTTC/ & 157 & Intron - Exon junction & 0.996 & $98.8 \%$ \\
\hline & & Rev- GAATCACCCTGGCAAGCATCTIIT & & & & \\
\hline Tub & Structural subunit & For- TGTGCCCAAGGATGTGAACG/ & 118 & 202 & 0.991 & $110.9 \%$ \\
\hline & & Rev- CACAGTGGGTGGTTGGTAGTTGAT & & & & \\
\hline RprolR76b & Ionotropic receptor co-receptor & For- GCGTTTGCGTACCAAATGGACA / & 113 & 1055 & 0.974 & $84.1 \%$ \\
\hline & & Rev- GCGTCCGGTAGATCCAAAGTGATT & & & & \\
\hline
\end{tabular}


products to confirm reaction specificity. Reactions for each sample were performed in three technical replicates. In all qRT-PCR experiments, no-template controls (NTC) were included in triplicates. PCR efficiencies (E) for each primer were determined using the slope of a linear regression model [35], which was obtained by measuring the quantification cycle $(\mathrm{Cq})$ for a range of 5fold serial dilutions of cDNA samples (except for Act that was obtained using a 3-fold serial dilution). Information about primers, amplicons and calibration curves is presented in Table 1.

\section{RT-PCR and sequencing}

The PCR reactions for the eight reference genes were performed for 35 cycles $\left(94^{\circ} \mathrm{C}\right.$ for $30 \mathrm{~s}, 60^{\circ} \mathrm{C}$ for $30 \mathrm{~s}$ and $72^{\circ} \mathrm{C}$ for $30 \mathrm{~s}$ ) with $2 \mu \mathrm{L}$ of pure cDNA, $2.2 \mu \mathrm{L}$ of a $1 \mathrm{mM}$ dNTP solution, $0.6 \mu \mathrm{L}$ of a $10 \mu \mathrm{M}$ primer solution, and $1 \mathrm{U}$ of Taq polymerase (Promega) in a final volume reaction of $20 \mu \mathrm{L}$. Expected amplicon sizes in PCR products were confirmed using $2 \%$ agarose gels visualized after GelRed ${ }^{\mathrm{TM}}$ staining (Biotium Inc, Hayward, CA, USA). Afterward, PCR products were purified using the Wizard Genomic DNA Purification Kit (Promega) and sequenced using both primers with the ABI Prism BigDye V 3.1 Terminator Cycle Sequencing kit and an ABI 3730 DNA sequencing system (Life Technologies). The consensus sequences were obtained using the Staden Package 2.0 [64] and verified by comparing them with the $R$. prolixus genomic database, using the basic local alignment search tool (BLASTn).

\section{Data analysis}

\section{Ranking candidate reference genes}

The geNorm [21] and Normfinder [65] algorithms were used to detect the most stable reference genes for each comparison using the GenEx software v. 5.4 (MultiD Analyses $\mathrm{AB}$, Sweden). geNorm estimates the gene expression stability measure (M-value) calculating the mean pairwise variation $(\mathrm{V})$ of each gene relative to all other genes included in the analysis. Genes with the lowest M-value are considered the most stable genes in the tested conditions. In calculation, at each step, the least stable gene is eliminated and an $\mathrm{M}$-value is recalculated until the two most stable genes are defined. Normfinder estimates the expression stability (reported as expression stability value or SV) in and between groups using a two-way ANOVA. According to Normfinder, genes with the lowest SV are the most stable. In our analysis, three different stability rankings were obtained, one from geNorm (based on M-value) and two from Normfinder (based on SV). Of these, one considered experimental groups (hereafter named as Normfinder ${ }^{\mathrm{W}}$ ), while the other omitted these groups (hereafter named as Normfinder).
Normfinder also allowed estimating the optimal number of reference genes needed for normalization by calculating the accumulated standard deviation (Acc. $\mathrm{SD})$ based on any number of reference genes. Therefore, the number of genes showing the lowest Acc. SD was used to determine how many genes to select to build normalization factors (NFs) for each comparison intended. This was estimated separately for female and male antennae for all comparisons studied. This algorithm also indicated the best pairwise combination of most stable genes. It is worth noting here that the mentioned combination was only used in those cases in which the optimal number of reference genes suggested by Normfinder was two.

\section{Normalization factor selection}

The NFs were created and evaluated for each condition following different steps. First, the optimal number of reference genes defined for each comparison was used to select the best genes according to geNorm and both Normfinder rankings. Subsequently, the geometric mean of the selected genes was calculated to create the corresponding NFs. Then, all NFs were ranked together with the single genes using the geNorm and Normfinder algorithms. Finally, the NF placed in best position after considering the three rankings was selected. In case of a tie in the latter step, both alternatives were tested to confirm that they did not alter the overall result.

The analysis of expression stability of candidate reference genes, the calculation of the optimal number of references genes and the selection of the NFs were performed to evaluate results separately for the antennae of males or females in 8 pairwise comparisons (four per sex): (i) 21 day-old unfed larvae and 21-day old fed larvae (effect of nutrition in larval bugs); (ii) 21 day-old unfed adults and 21-day old fed adults (effect of nutrition in adults); (iii) 21-day old unfed larvae compared to 1 day-old unfed adults (effect of moulting); (iv) 1 dayold unfed adults compared to 21 day-old unfed adults (effect of maturation in adults).

\section{Normalization process over different approaches}

To highlight the influence of the normalization process on the analysis of gene expression data from qRT-PCR, the transcript abundance for an olfactory co-receptor gene (RproIR76b) was analyzed in the conditions earlier described using two different normalization approaches. The RproIR76b dataset used for this purpose has been generated (and has been already used) for the purpose of studying molecular aspects of triatomine bug olfaction and is here used to exemplify the impact of reference gene selection on normalization processes (Latorre-Estivalis et al., submitted). First, qRT-PCR data were normalized using the best reference gene or the best normalization factor obtained as previously explained. In the second 
approach, the normalization was performed using the least stable candidate reference gene according to the rankings generated by geNorm, Normfinder and Normfinder ${ }^{\mathrm{W}}$. For each treatment, fold-change values were subjected to statistical analysis to estimate the influence of data treatment on the expression profile of the olfactory receptor gene. Data were analyzed using the Kolmogorov-Smirnov test to check normality using the Graph-Pad Prism ${ }^{\bullet}$ (5.0) software. Data not satisfying normality assumptions were Log transformed. Finally, a two-tailed $t$-test for pair-wise comparisons was performed considering probabilities of $p<0.05$ as significant.

\section{Results}

\section{Expression profiles of candidate reference genes}

The expression of the eight reference genes in $R$. prolixus antennae was initially confirmed by the presence of a single band of the expected size in $2 \%$ electrophoresis agarose gels. Amplicon sequencing confirmed the specificity and correct design of all primers. The presence of a single-peak in the dissociation curve obtained at the final step of qRT-PCR also validated primer specificity. The qRT-PCR efficiency and determination coefficient $\left(\mathrm{R}^{2}\right)$ of each gene are detailed on Table 1 . Reaction efficiency varied from $88.2 \%(A c t)$ and $110.9 \%$ (Tub) and the regression coefficients ranged between $0.999(S D H)$ to 0.987 (GST). The raw quantification cycle (Cq) values were situated between $20.4(\mathrm{Tub})$ and $29.3(\mathrm{Act})$ in female antennae and between 20.9 (eIF-1a) and 29.5 (Act) in male antennae (Figure 1).

\section{Analysis of gene expression stability}

All algorithms previously mentioned were used to calculate gene expression stability for the eight candidate reference genes in all comparisons. Candidate reference genes were ranked separately for females (Table 2) and males (Table 3) from the most to the least stable considering their average expression stabilities (M-values from geNorm) and their expression stability values (SVs from Normfinder and Normfinder ${ }^{\mathrm{W}}$ ).

\section{The effect of nutrition}

In all three rankings obtained for antennae of unfed and fed female larvae $T u b$ was the most stable gene, while $S p$ was the least stable one (Table 2). The five most stable genes for this comparison (Tub, GAPDH, GST, G6PDH and $S D H)$ and three least stable genes (eIF-1a, Act and $S p$ ) were the same in the three rankings generated. In this case, the combination of G6PDH-GST was suggested as the best option by Normfinder ${ }^{\mathrm{W}}$.

All genes had a stable expression profile when unfed and fed male larvae antennae were compared, as the highest $\mathrm{M}$ and $\mathrm{SV}$ values were 0.59 and 0.80 , respectively (Table 3). In this case, the most stable gene was G6PDH, which was ranked first by geNorm and Normfinder ${ }^{\mathrm{W}}$, while $e I F-1 a$, Act and $S p$ were again ranked in the last positions. For this comparison the best combination suggested by Normfinder ${ }^{\mathrm{W}}$ was SDH-GST.

As with female larvae, the comparison of expression patterns from antennae of unfed and fed female adults showed that Tub was the most stable gene (Table 2). All candidate reference genes were very stable between these conditions, with highest $\mathrm{M}$ and $\mathrm{SV}$ values of 0.53 and 0.57 , respectively (Table 2). Similarly as with female larvae, eIF-1a, Sp and Act were characterized as unstable genes, although GST was also unstable in female adults. The two rankings obtained with Normfinder were identical except for the position of G6PDH and $S D H$. Despite $e I F-1 a$ was not ranked in top positions in any of the rankings, this gene together with G6PDH were considered as the best combination by Normfinder ${ }^{\mathrm{W}}$.

Feeding male adults did not seem to affect the stability of this set of genes, and $S D H$ was identified as the most
FEMALE

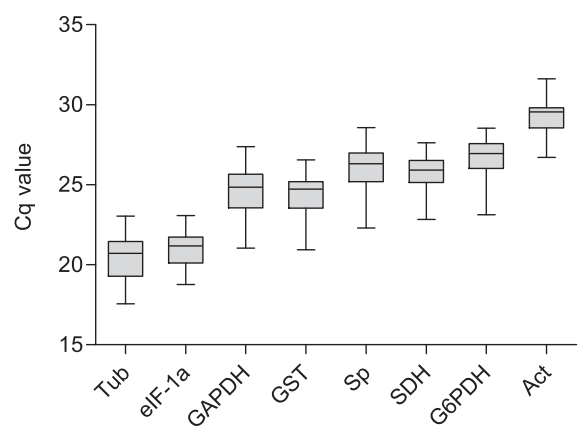

MALE

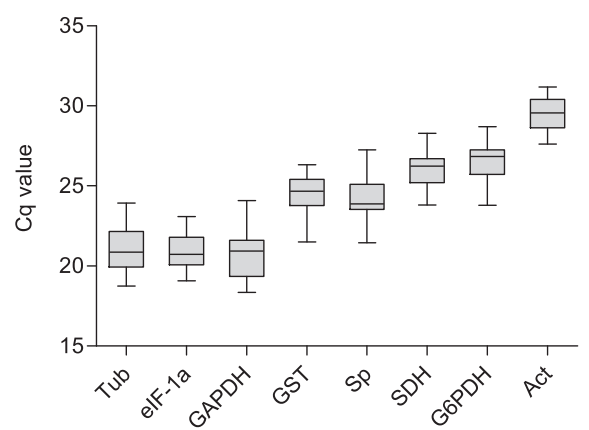

Figure 1 Expression levels of candidate reference genes in female and male antennae of $R$. prolixus. Grey bars indicate the 25/75 percentiles, whisker caps indicate the 10/90 percentiles, and the line marks means. Cq: quantitative cycle. 
Table 2 Gene expression stability rankings for the different physiological conditions studied in female antennae

\begin{tabular}{|c|c|c|c|c|c|c|c|c|c|c|c|c|}
\hline \multirow{2}{*}{$\begin{array}{l}\text { Ranking } \\
\text { position }\end{array}$} & \multicolumn{3}{|c|}{ Effect of nutrition in larvae } & \multicolumn{3}{|c|}{ Effect of nutrition in adults } & \multicolumn{3}{|c|}{ Imaginal moult effect } & \multicolumn{3}{|c|}{ Adult maturation effect } \\
\hline & geNorm & NormFinder & NormFinder ${ }^{w}$ & geNorm & NormFinder & NormFinder $^{w}$ & geNorm & NormFinder & NormFinder $^{w}$ & geNorm & NormFinder & NormFinder $^{n}$ \\
\hline \multirow[t]{2}{*}{1} & Tub/GAPDH & Tub & Tub & G6PDH/GAPDH & Tub & Tub & $\mathrm{G} 6 \mathrm{PDH} / \mathrm{SDH}$ & $\mathrm{SDH}$ & SDH & $\mathrm{Sp} / \mathrm{GAPDH}$ & Tub & Tub \\
\hline & $(0.215)$ & $(0.079)$ & $(0.083)$ & $(0.327)$ & $(0.186)$ & $(0.169)$ & $(0.387)$ & $(0.193)$ & $(0202)$ & $(0.345)$ & $(0.271)$ & $(0.268)$ \\
\hline \multirow[t]{2}{*}{2} & - & $\mathrm{SDH}$ & G6PDH & - & G6PDH & $\mathrm{SDH}$ & - & GAPDH & GAPDH & - & G6PDH & G6PDH \\
\hline & & $(0.155)$ & $(0.125)$ & & $(0.256)$ & $(0.232)$ & & $(0.217)$ & $(0.208)$ & & $(0.284)$ & $(0.326)$ \\
\hline \multirow[t]{2}{*}{3} & GST & GST & GST & Tub & $\mathrm{SDH}$ & G6PDH & GAPDH & G6PDH & Act & G6PDH & $\mathrm{SDH}$ & $\mathrm{SDH}$ \\
\hline & $(0.251)$ & $(0.171)$ & $(0.133)$ & $(0.352)$ & $(0.269)$ & $(0.253)$ & $(0.476)$ & $(0.431)$ & $(0.323)$ & $(0.393)$ & $(0.3)$ & $(0.326)$ \\
\hline \multirow[t]{2}{*}{4} & G6PDH & G6PDH & SDH & elF-1a & GAPDH & GAPDH & Act & Act & G6PDH & Tub & $\mathrm{Sp}$ & GST \\
\hline & $(0.272)$ & $(0.2)$ & $(0.158)$ & $(0.388)$ & $(0.331)$ & $(0.261)$ & $(0.543)$ & $(0.492)$ & $(0.478)$ & $(0.42)$ & $(0.515)$ & $(0.403)$ \\
\hline \multirow[t]{2}{*}{5} & $\mathrm{SDH}$ & GAPDH & GAPDH & $\mathrm{SDH}$ & elF-1a & elF-1a & $\mathrm{Sp}$ & Sp & $\mathrm{Sp}$ & $\mathrm{SDH}$ & GST & $\mathrm{Sp}$ \\
\hline & $(0.301)$ & $(0.268)$ & $(0.18)$ & $(0.407)$ & $(0.35)$ & $(0.267)$ & $(0.578)$ & $(0.607)$ & $(0.570)$ & $(0.515)$ & $(0.533)$ & $(0.51)$ \\
\hline \multirow[t]{2}{*}{6} & elF-1a & elF-1a & Act & Sp & Sp & Sp & GST & Tub & Tub & GST & GAPDH & GAPDH \\
\hline & $(0.348)$ & $(0.494)$ & $(0.306)$ & $(0.444)$ & $(0.474)$ & $(0.288)$ & $(0.629)$ & $(0.704)$ & $(0.692)$ & $(0.56)$ & $(0.568)$ & $(0.548)$ \\
\hline \multirow[t]{2}{*}{7} & Act & Act & elF-1a & GST & GST & GST & Tub & GST & GST & elF-1a & elF-1a & elF-1a \\
\hline & $(0.406)$ & $(0.502)$ & $(0.333)$ & $(0.485)$ & $(0.508)$ & $(0.305)$ & $(0.708)$ & $(0.823)$ & $(0.811)$ & $(0.618)$ & $(0.589)$ & $(0.559)$ \\
\hline \multirow[t]{5}{*}{8} & Sp & Sp & Sp & Act & Act & Act & elF-1a & elF-1a & elF-1a & Act & Act & Act \\
\hline & $(0.523)$ & (0.888) & $(0.395)$ & $(0.529)$ & $(0.575)$ & $(0.345)$ & $(0.799)$ & $(0.997)$ & $(0.955)$ & $(0.736)$ & $(1.052)$ & $(0.902)$ \\
\hline & & & $\begin{array}{l}\text { Best } \\
\text { combination }\end{array}$ & & & $\begin{array}{l}\text { Best } \\
\text { combination }\end{array}$ & & & $\begin{array}{l}\text { Best } \\
\text { combination }\end{array}$ & & & $\begin{array}{l}\text { Best } \\
\text { combination }\end{array}$ \\
\hline & & & GP6PDH-GST & & & G6PDH-elF-1a & & & GAPDH-SDH & & & G6PDH-SDH \\
\hline & & & $(0.068)$ & & & $(0.101)$ & & & $(0.077)$ & & & $(0.079)$ \\
\hline
\end{tabular}

geNorm and Normfinder rankings were built using M-value and stability value, respectively. The Normfinder ranking did not take experimental groups into account, while the Normfinder ${ }^{\mathrm{w}}$ one considered them for the analysis of expression stability. 
Table 3 Gene expression stability rankings for the different physiological conditions studied in male antennae

\begin{tabular}{|c|c|c|c|c|c|c|c|c|c|c|c|c|}
\hline \multirow[t]{2}{*}{ Rankingposition } & \multicolumn{3}{|c|}{ Effect of nutrition in larvae } & \multicolumn{3}{|c|}{ Effect of nutrition in adults } & \multicolumn{3}{|c|}{ Imaginal moult effect } & \multicolumn{3}{|c|}{ Adult maturation effect } \\
\hline & geNorm & NormFinder & NormFinder ${ }^{w}$ & geNorm & NormFinder & NormFinder ${ }^{w}$ & geNorm & NormFinder & NormFinder ${ }^{w}$ & geNorm & NormFinder & NormFinder ${ }^{w}$ \\
\hline \multirow[t]{2}{*}{1} & G6PDH/GAPDH & SDH & G6PDH & $\mathrm{SDH} / \mathrm{Tub}$ & SDH & SDH & SDH/GAPDH & Act & $\mathrm{SDH}$ & GST/G6PDH & G6PDH & Sp \\
\hline & $(0.14)$ & $(0.051)$ & $(0.141)$ & $(0.306)$ & $(0.259)$ & $(0.155)$ & $(0.332)$ & $(0.423)$ & $(0.283)$ & $(0.378)$ & $(0.421)$ & $(0.296)$ \\
\hline \multirow[t]{2}{*}{2} & & G6PDH & $\mathrm{SDH}$ & & GAPDH & Act & - & GAPDH & GAPDH & - & Sp & GST \\
\hline & & $(0.128)$ & $(0.164)$ & - & $(0.265)$ & $(0.195)$ & & $(0.424)$ & $(0.293)$ & & $(0.447)$ & $(0.334)$ \\
\hline \multirow[t]{2}{*}{3} & Tub & GAPDH & GAPDH & GAPDH & Tub & G6PDH & Act & G6PDH & Sp & elF-1a & Tub & G6PDH \\
\hline & $(0.215)$ & $(0.162)$ & $(0.18)$ & $(0.361)$ & $(0.298)$ & $(0.212)$ & (0.419) & $(0.426)$ & (0.313) & (0.494) & $(0.452)$ & $(0.391)$ \\
\hline \multirow[t]{2}{*}{4} & $\mathrm{SDH}$ & Tub & Tub & Act & Act & Tub & G6PHD & $\mathrm{SDH}$ & Act & $\mathrm{Sp}$ & elF-1a & $\mathrm{SDH}$ \\
\hline & $(0.227)$ & (0.195) & $(0.224)$ & $(0.39)$ & $(0.331)$ & $(0.214)$ & $(0.536)$ & $(0.432)$ & $(0.410)$ & $(0.564)$ & $(0.454)$ & (0.399) \\
\hline \multirow[t]{2}{*}{5} & GST & GST & GST & G6PDH & G6PDH & GAPDH & GST & Sp & G6PDH & Tub & GST & Tub \\
\hline & (0.319) & (0.35) & $(0.344)$ & $(0.423)$ & $(0.375)$ & $(0.244)$ & (0.578) & $(0.492)$ & $(0.426)$ & (0.599) & $(0.511)$ & $(0.411)$ \\
\hline \multirow[t]{2}{*}{6} & Act & Act & $S p$ & GST & GST & GST & Sp & Tub & Tub & $\mathrm{SDH}$ & $\mathrm{SDH}$ & elF-1a \\
\hline & (0.399) & (0.628) & (0.499) & $(0.484)$ & $(0.504)$ & $(0.246)$ & (0.615) & $(0.544)$ & (0.528) & (0.659) & $(0.527)$ & $(0.429)$ \\
\hline \multirow[t]{2}{*}{7} & elF-1a & elF-1a & Act & elF-1a & elF-1a & elF-1a & Tub & GST & GST & Act & Act & GAPDH \\
\hline & $(0.486)$ & (0.697) & $(0.577)$ & $(0.52)$ & (0.519) & $(0.325)$ & $(0.665)$ & $(0.631)$ & $(0.617)$ & $(0.687)$ & $(0.634)$ & $(0.543)$ \\
\hline \multirow[t]{5}{*}{8} & Sp & Sp & elF-1a & Sp & Sp & Sp & elF-1a & elF-1a & elF-1a & GAPDH & GAPDH & Act \\
\hline & (0.578) & (0.8) & (0.636) & (0.598) & (0.779) & $(0.35)$ & $(0.726)$ & $(0.806)$ & $(0.767)$ & $(0.715)$ & $(0.64)$ & $(0.571)$ \\
\hline & & & $\begin{array}{l}\text { Best } \\
\text { combination }\end{array}$ & & & $\begin{array}{l}\text { Best } \\
\text { combination }\end{array}$ & & & $\begin{array}{l}\text { Best } \\
\text { combination }\end{array}$ & & & $\begin{array}{l}\text { Best } \\
\text { combination }\end{array}$ \\
\hline & & & SDH-GST & & & Act-SDH & & & Tub-GST & & & G6PDH-elF-1a \\
\hline & & & $(0.126)$ & & & $(0.114)$ & & & $(0.149)$ & & & $(0.156)$ \\
\hline
\end{tabular}

geNorm and Normfinder rankings were built using M-value and stability value, respectively. The Normfinder ranking did not take experimental groups into account, while the Normfinder ${ }^{\mathrm{w}}$ one considered them for the analysis of expression stability. 
stable gene (Table 3). In fact, all genes showed good expression stability (maximum $\mathrm{M}$-value $=0.59$ and maximum $S V=0.77$ ). In this comparison geNorm and both Normfinder rankings were identical except for the GAPDH and Tub. The GST, eIF-1a and Sp genes were characterized as the worst by geNorm and both Normfinder rankings. Curiously and contrasting the three previous comparisons, Act was not ranked in the lowest four ranking positions. Interestingly, the expression levels of $e I F-1 a$ and $S p$ genes were the most unstable when the antennae of larval and adult males were compared.

\section{The effect of imaginal moult}

In the comparison of unfed 21 day-old female larvae against 1-day old adult females, the stability of all candidate genes decreased as the highest $\mathrm{M}$ and $\mathrm{SV}$ values were 0.79 and 0.99 , respectively (Table 2 ). For the corresponding comparison in males $\mathrm{M}(0.72)$ and SV (0.80) values were slightly lower (Table 3 ). Coincidently, the comparison of the effect of development on gene expression in female and male antennae showed $S D H$ and $G A P D H$ as the most stable genes. On the other hand, $S p, T u b, G S T$ and $e I F-1 a$ were ranked in the last four positions both in female and male rankings.

\section{The effect of adult maturation}

Female maturation during the first phase of imaginal life (1 day-old $v s$ 21-day-old) affected Tub and G6PDH the least (Table 2). M-values varied from 0.35 ( $S p$ and GAPDH) to $0.73(A c t)$, while SV-values ranged from 0.27 to 1.05 in Normfinder and from 0.26 to 0.9 in Normfinder ${ }^{\mathrm{W}}$. Except for the order of GST and Sp, both Normfinder rankings were identical in this case. eIF-1a and Act genes were considered as the least stable genes taking into account the results from the three rankings. Normfinder ${ }^{\mathrm{W}}$ proposed the combination of G6PDH and $S D H$ as the most stable for comparing the effect of imaginal maturation in female antennae.

The rankings generated by geNorm and Normfinder when 1 day-old and 21 day-old males were compared were quite different and only the positions of Act and $G A P D H$ as the least stable genes matched all classifications (Table 3). The analysis suggested G6PDH as the most stable gene for this comparison due to the fact that it was ranked first in two of the rankings.

\section{Calculation of the optimal number of reference genes for data normalization}

The number of genes which when combined showed the lowest accumulated standard deviation (Acc. SD) was selected for each experimental condition studied using geNorm (Figure 2). The optimal number of genes to be used in normalization procedures for the five different treatments ranged from only one, up to eight (i.e., all genes studied). Four genes were enough to normalize expression values in antennae from unfed and fed female larvae. In antennae from male larvae, this normalization could be performed with only one gene. For both sexes, the optimal number of reference genes to normalize expression data from antennae of unfed and fed adults was five. Regarding moulting and developmental effects on female antennae, the ideal number of genes to normalize gene expression values were two and three, respectively. In contrast, the comparison of gene expression on male antennae from unfed larvae and 1-day old adults would require combining the seven most stable genes. Finally, to analyze the developmental effect in male adults, all 8 potential reference genes would be necessary for an optimal normalization process.

\section{Normalization factor construction}

The elaboration of NFs for the various conditions analyzed in female antennae was laborious. In the experiment about the effect of adult nutrition, the combination of G6PDH-GAPDH-Tub-eIF-1a and SDH was selected (see Table 4). For the other experiments with females, the absence of consensus between different rankings made additional comparisons necessary. In these cases, different NFs were created and subsequently compared in an iterative manner (Table 4). In the case of the experiment on larval nutrition, the number of genes recommended by Normfinder was four, and two different NFs were created: one (TubGST-G6PDH-GAPDH) based on the geNorm stability ranking and another (Tub-GST-G6PDH-SDH) based on the Normfinder stability rankings described in Table 2. Both NFs showed high stability $(\mathrm{M}$-value $=0.1$ and maximum SV $=0.06$ ) and they were ranked first in the three new rankings. The result of the rankings made it impossible to select a NF between the two better ranked for comparing nutrition effects on antennae of female larvae. Therefore, normalization was performed using both NFs separately and the results obtained were compared to confirm that the different NFs ranked as best did not alter the conclusions reached in this case. For the experiment testing the effect of development to the adult phase in female antennae, two combinations, including the best pairs of genes from geNorm (G6PDH-SDH) and Normfinder (G6PDH-SDH), were also very stable (Table 4). When ranked in a second round, the Normfinder combination appeared as best in all rankings. Finally, two different factors with three different genes were generated for the maturation experiment on adult female antennae: G6PDH-Sp-GAPDH (geNorm) and G6PDHSDH-Tub (Normfinder and Normfinder ${ }^{\mathrm{W}}$ ), the latter being the most stable (Table 4). The NFs chosen for 


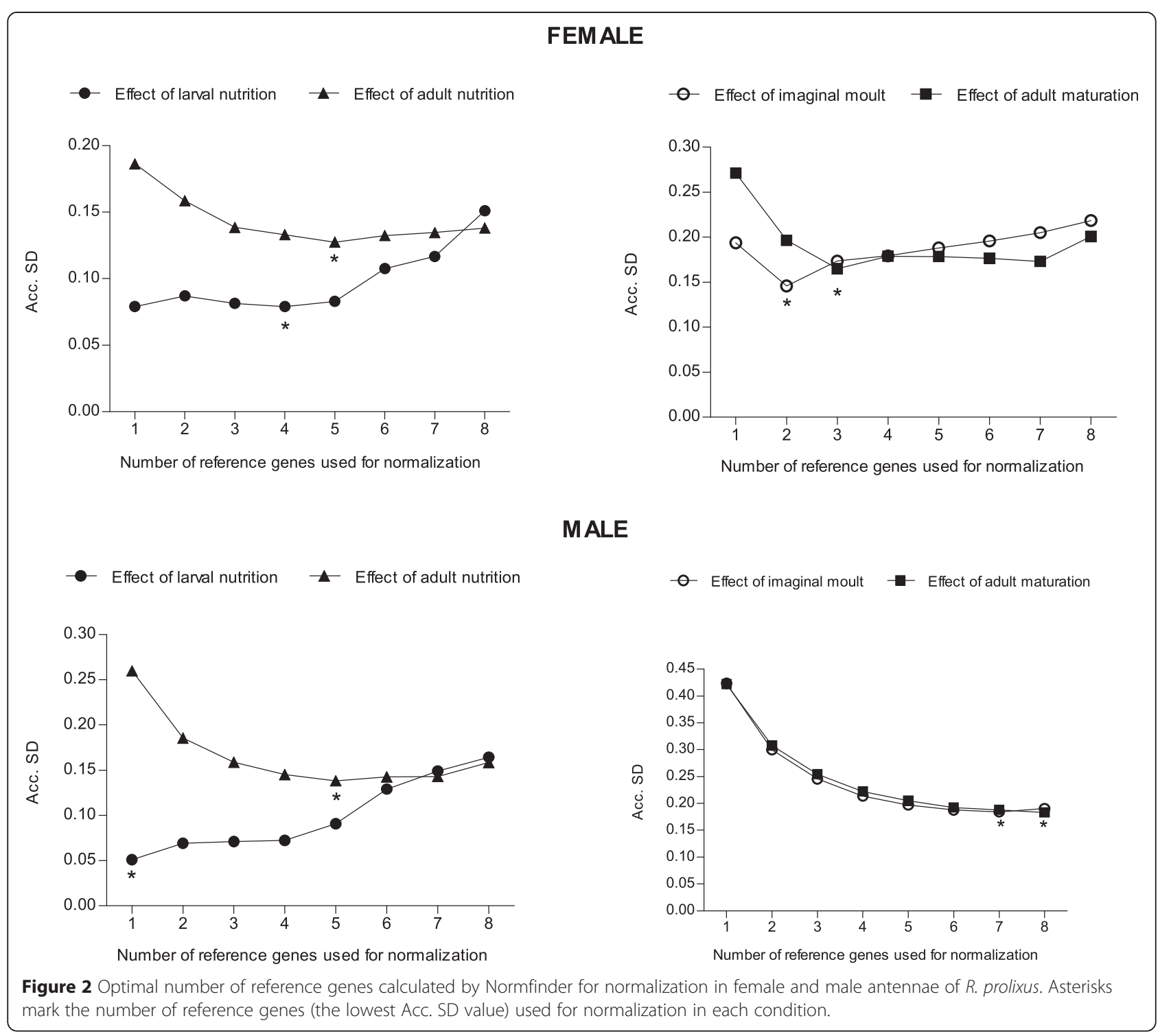

the different experiments on the antennae of females are described in Table 5 .

The G6PDH gene, ranked best in all three rankings (Table 3) would be the choice to normalize expression data from the nutrition experiment with male larvae. The combination of SDH-Tub-GAPDH-Act and G6PDH (these five genes appear in the first positions in all rankings, see Table 3) would be the choice to normalize expression data from the nutrition experiment performed with male adult antennae. To compare gene expression levels in antennae of larval and recently emerged adult males, all genes except for eIF-1a (see Table 3) would be needed. Besides, the combination of all genes would be required to compare gene expression data between antennae of 1 and 21 day-old male adults. All NFs selected for males are detailed on Table 5.
Verifying the effect of different normalization strategies on the expression profile calculated for a target gene

Two different approaches were used to evaluate the expression levels of an olfactory co-receptor gene in the antennae of female and male bugs for the comparisons listed above. In a first case, normalization was performed with the NFs described in Table 4. Alternatively, the same process was performed using the least stable gene selected according to the stability rankings calculated (see Tables 2 and 3). Interestingly, in only three of the eight comparisons performed, both normalization approaches produced identical results, i.e., with both adult nutrition experiments (Figure $3 \mathrm{~b}$ and $\mathrm{f}$ ) and male adult maturation (Figure 3h). For all other comparisons, the conclusions about stability, increase or decrease on gene expression were altered, such as with female 
Table 4 Stability values of the female normalization factors

\begin{tabular}{|c|c|c|c|c|c|c|c|c|}
\hline \multicolumn{3}{|c|}{ Effect of nutrition in larvae } & \multicolumn{3}{|c|}{ Imaginal moult effect } & \multicolumn{3}{|c|}{ Adult maturation effect } \\
\hline geNorm & NormFinder & NormFinder ${ }^{w}$ & geNorm & NormFinder & NormFinder ${ }^{w}$ & geNorm & NormFinder & NormFinder ${ }^{w}$ \\
\hline Tub-GST- & Tub-GST- & Tub-GST- & & & & & & \\
\hline G6PDH-GAPDH & G6PDH-GAPDH & G6PDH-GAPDH & SDH-GAPDH & SDH-GAPDH & SDH-GAPDH & G6PDH-Sp-GAPDH & G6PDH-Sp-GAPDH & G6PDH-Sp-GAPDH \\
\hline$(0.103)$ & $(0.047)$ & $(0.065)$ & $(0.241)$ & $(0.193)$ & $(0.076)$ & $(0.257)$ & $(0.35)$ & $(0.366)$ \\
\hline Tub-GST- & Tub-GST- & Tub-GST- & G6PDH-SDH & G6PDH-SDH & G6PDH-SDH & G6PDH-Tub-SDH & G6PDH-Tub-SDH & G6PDH-Tub-SDH \\
\hline G6PDH-SDH & G6PDH-SDH & G6PDH-SDH & $(0.191)$ & $(0.217)$ & $(0.251)$ & $(0.303)$ & $(0.116)$ & $(0.038)$ \\
\hline \multirow[t]{5}{*}{ (0.103) } & $(0.0516)$ & $(0.055)$ & & & & & & \\
\hline & & Best gen & & & Best gen & & & Best gen \\
\hline & & Tub-GST- & & & & & & \\
\hline & & G6PDH-SDH & & & SDH-GAPDH & & & G6PDH-Tub-SDH \\
\hline & & $(0.055)$ & & & $(0.076)$ & & & $(0.038)$ \\
\hline
\end{tabular}


Table 5 Genes used for building the best normalization factors for each experimental comparison

\begin{tabular}{lllll}
\hline & Effect of nutrition in larvae & Effect of nutrition in adults & Imaginal moult effect & Adult maturation effect \\
\hline Female antennae & $\begin{array}{l}\text { Tub-GAPDH-GST-G6PDH } \\
\text { or Tub-GAPDH-GST-SDH }\end{array}$ & G6PDH-GAPDH-Tub-elF-1a-SDH & SDH-GAPDH & G6PDH-Tub-SDH \\
Male antennae & G6PDH & SDH-Tub-GAPDH-Act-G6PDH & All genes except elF-1a & All genes \\
\hline
\end{tabular}

For comparing the effect of feeding on gene expression in the antennae of female larvae it was impossible to select only one NF and both best ranked gene associations were included in the table.

larvae nutrition (Figure 3a) or female adult maturation (Figure 3d).

\section{Discussion}

A current objective of diverse insect olfaction studies is to understand the molecular basis of olfactory detection, by associating transcription profiles with physiological conditions. The qRT-PCR technique has been widely used in these studies, and to validate molecular techniques such as RNA interference [66] or RNA-Seq [27,67]. In this study, a set of eight candidate reference genes was evaluated in the antennae of an insect vector in five different conditions for both sexes. The importance of using a suitable normalization approach in olfactory gene studies based on qRT-PCR was shown.

In qRT-PCR experiments, testing potential reference genes enables the use of the most stable internal controls from a panel of candidate genes. A number of 'housekeeping genes' involved in basic cellular functions, such as energy production or cell division, have been commonly used reference genes. Many of these genes work well for RT-PCR where end point determination is done, and are useful candidates in qRT-PCR. However, the expression of these genes may be regulated under certain physiological comparisons; e.g. the expression of GAPDH has been shown to be subject to regulation in intestinal tissues after blood ingestion in triatomines [38]. For this reason, evaluating a set of candidate reference genes is necessary for each combination of species, tissues, sex and physiological conditions tested in order to avoid inconsistent results. Considering the geNorm and Normfinder stability rankings and the normalization factors (NFs) created in our study, the most stable genes in Rhodnius antennae were G6PDH, Tub, GAPDH and $S D H$. In fact, $S D H$ was ranked in the top positions in all the comparisons, except for fed male larvae. Tub has already been reported as a stable gene in salivary glands and crops of $R$. prolixus [38].

The use of an inappropriate normalization protocol impacts directly on the interpretation of results, as shown by the analysis of RproIR76b expression. A potential impact could be a misleading statistical result, an increased variation between replicates or even a reversal of the regulation direction reported. The importance of this aspect is reflected by the example used in our study, where transcriptional signal changes depended on the stability of the reference genes chosen. For example, there were no significant differences in expression between larvae and adults from both sexes using the combination of the most stable genes. Instead a clear, but false, increase in RproIR76b expression was generated when qRT-PCR data were normalized using an unstable gene as eIF-1a (Figure 3). A similar situation was observed with male larvae when data were normalized using eIF-1a; according to these calculations, feeding induced a false up-regulation of RproIR76b expression, while normalization with the most stable gene combination resulted in an opposite effect (Figure 3). Majerowicz et al. [47] observed that eIF-1a was useful to normalize gene expression data from different tissues, such as the posterior midgut, ovary and fat body. In the same study, Act was identified as a stable gene in the ovaries. This last candidate is one of the first genes proposed as a reference for normalization in qRT-PCR [68]. In contrast, we observed that the least stable genes in $R$. prolixus antennae were $S p$, eIF-1 $1 a$ and Act. Our study demonstrates that reference gene stability can change between physiological conditions, tissues and sexes within the same species, showing the limitations of adopting previously used reference genes in qPCR experiments.

The number of genes used to create the normalization factors is also a critical point in the normalization process. Although we selected a number of genes as most reliable references, it is still possible that other genes not tested would emerge as more stable for these comparisons. For instance, even with a panel of eight potential reference candidates, all genes were necessary to create the most stable normalization factor in the experiment studying the effect of male development. This highlights the importance of evaluating a relevant number of genes to allow a proper normalization process to find the most stable combination of genes available [32].

The use of reference gene selection software was not a straightforward process in our study. Particularly, the different softwares generated stability rankings that after comparing them, evinced several inconsistencies. It would be desirable that the different approaches end up with the same genes ranked as best candidates, especially when targeting multiple treatments and comparisons. 


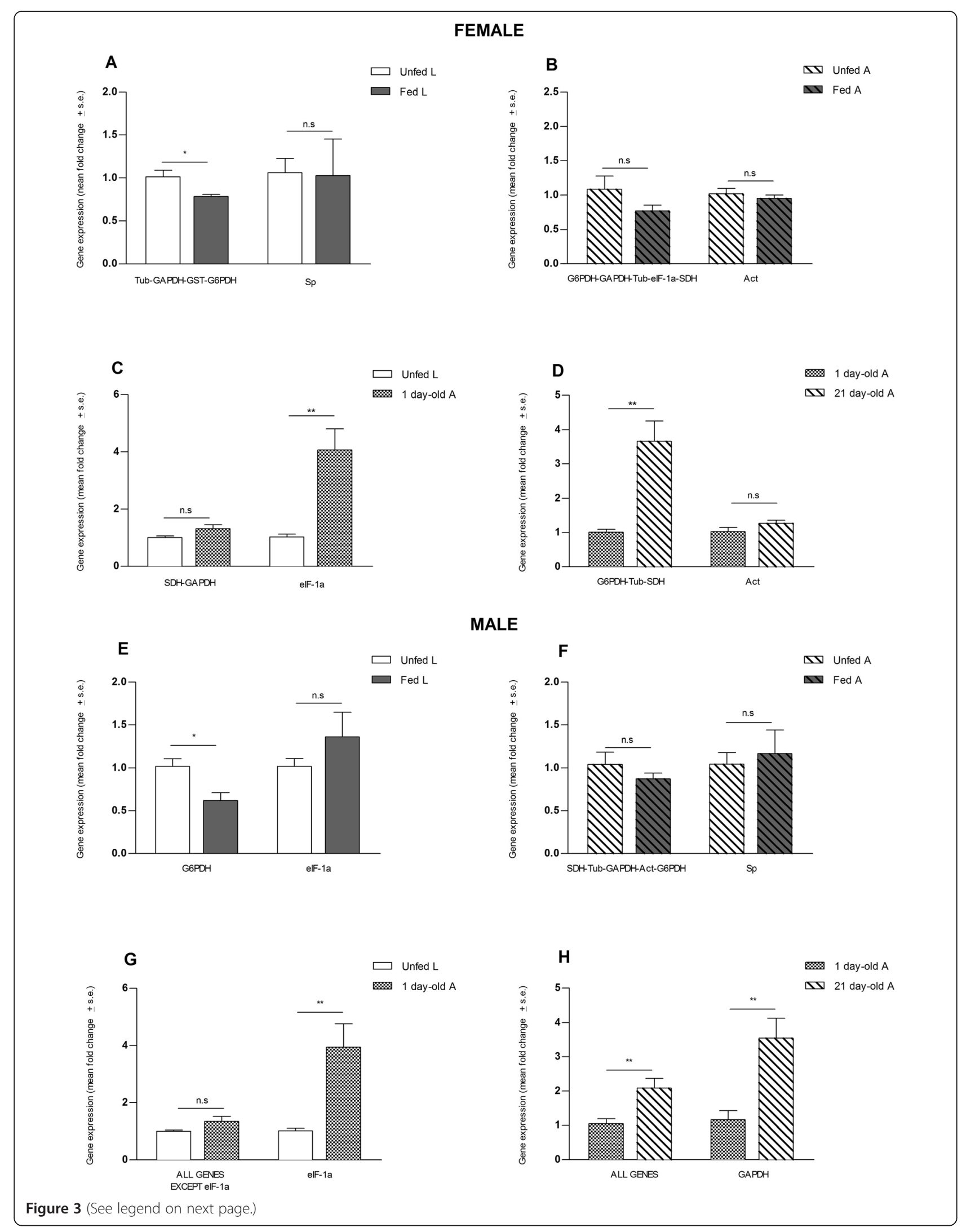


(See figure on previous page.)

Figure 3 Relative expression of RprolR76b in female and male antennae of R. prolixus using different normalization approaches. Two normalization approaches were used: applying the best normalization factor (left) and the worst potential reference gene (right). (A) Effect of nutrition in antennae of female larvae; (B) Effect of nutrition in antennae of female adults; (C) Effect of imaginal moulting in female antennae; (D) Effect of adult maturation in antennae of female adults; (E) Effect of nutrition in antennae of male larvae; (F) Effect of nutrition in antennae of male adults; (G) Effect of imaginal moulting in male antennae; and $\mathbf{H} \mathbf{H}$ Effect of adult maturation in antennae of male adults. Significant differences were calculated by using a two-tailed $t$-test for pair-wise comparisons. Asterisks denote statistically significant differences, ${ }^{*} p<0.01$; ${ }^{* *} p<0.01$ and ${ }^{* * *} p<0.0001$. Error bars represent the standard error generated from 6 replicates per condition. L: larvae; A: adult; n.s.: non-significant difference.

However, a consensus of the best gene or genes was not always possible. One problem in selecting reference genes observed with the software we used was that stability indicators of a single gene are always tied to those of the other genes considered in the same panel and to the elimination method used. geNorm uses an elimination approach to arrive at the most stable pair of genes based on cumulative standard deviation, while Normfinder uses pairwise stability of single or selected groups of genes. Used alone, Normfinder might therefore find two co-regulated genes as most stable combination. However across analysis software, reference factors comprising of more than one reference gene always emerged more stable than the single genes alone. Therefore considering a batch of the most stable individual genes together to design a reference factor provides a more reliable means of normalization irrespective of method of choice of the internal calibrator.

\section{Conclusions}

This study underlines the need for an appropriate selection of internal normalization factors (and genes) for qPCR studies. We showed that, for genes with slight regulation, accurate normalization could, in fact change, the regulation signal obtained. This study further reiterates that while some traditionally used genes are an important starting point, new studies in specific tissues and treatment conditions need to objectively validate them for those conditions. For olfactory genes, such validation is much more important given the low expression levels of many genes in this system making the genes especially sensitive to regulatory changes acting on genes used as reference factors. The genome of $R$. prolixus will be published soon and is expected to lead to transcriptomics studies by qRT-PCR or RNA-Seq. Olfaction has also become a focus of studies looking after behavioural modification of pests and vector species [50]. Insect olfaction is known to be plastic and often regulated by the physiological needs of a species. Together, these facts would be expected to result in a rise in genomic studies of olfaction, and the attendant need for rigorous normalization protocols. This study is therefore an important step, and to our knowledge the first focusing on normalization procedures for the study of olfactory genes of insect vector species.

\section{Additional file}

Additional file 1: Table S1. Candidate reference genes, orthologous sequences used for tBLASTn searches, supercontig location of candidate genes in the $R$. prolixus genome, VectorBase gene codes and number of exons and number of amino-acids.

\section{Abbreviations}

qRT-PCR: Quantitative reverse transcription polymerase chain reaction; mRNA: messenger RNA; Tub: a-tubulin; Act: $\beta$-actin; GAPDH: Glyceraldehyde3-phosphate dehydrogenase; elF-1a: Eukaryotic initiation factor $1 A$; GST: Glutathione-S-transferase; Sp: Serine protease; SDH: Succinate dehydrogenase; G6PDH: Glucose-6-phosphate dehydrogenase; bp: Base pairs; HRM: High resolution melt; NTC: Non-template controls;

Cq: Quantification cycle; M-value: Gene expression stability measure; V: Pairwise variation; SV: Stability value; ANOVA: Analysis of variance; Normfinder $^{W}$ : Normfinder without treatments; Acc. SD: Accumulated standard deviation; NFs: Normalization factors; RprolR76b: Rhodnius prolixus ionotropic receptor $76 b$.

\section{Competing interests}

The authors declare that the research was conducted in the absence of any commercial or financial relationships that could be construed as a potential conflict of interest.

\section{Authors' contributions}

MGL conceived the project. MGL, BAO and JML designed the experiments and performed data analysis. $\mathrm{BAO}, \mathrm{JML}$ and $\mathrm{IHRO}$ carried out the experiments and provided experimental data. MGL, BAO, JML and RI wrote and provided comments on the manuscript. All authors read and approved the final manuscript.

\section{Acknowledgements}

The authors wish to thank the Program for Technological Development in Tools for Health-PDTIS-FIOCRUZ for having facilitated the use of its facilities. We wish to thank Mercedes Carolina Soares da Silva for her help in processing samples used in our experiments. Authors are indebted to INCTEM (Project number: 573959/2008-0), FAPEMIG (Project number: APQ-01359-11), PROEP-FIOCRUZ (Project number: 401973/2012-3), CNPq (Project number: 483805/2013-0), FIOCRUZ Visiting researcher fellowship program (fellowship JMLE 550017/2012-7), and the Linnaeus initiative 'Insect Chemical Ecology, Ethology and Evolution' IC-E3 (Formas, SLU).

\section{Author details}

${ }^{1}$ Chemical Ecology Unit, Department of Plant Protection Biology, SLU, Alnarp, Sweden. ${ }^{2}$ Current address: Bioversity International, Consultative Group for International Agricultural Research, Bujumbura, Burundi. ${ }^{3}$ Vector Behavior and Pathogen Interaction Group, Centro de Pesquisas René Rachou, FIOCRUZ, Belo Horizonte, Minas Gerais, Brazil. 
Received: 12 January 2015 Accepted: 15 April 2015

Published online: 22 April 2015

\section{References}

1. Guhl F, Pinto N, Aguilera G. Sylvatic triatominae: a new challenge in vector control transmission. Mem Inst Oswaldo Cruz. 2009;104 Suppl 1:71-5.

2. Lent H, Wygodzinsky P. Revision of the triatominae (Hemiptera, Reduviidae), and their significance as vectors of Chagas' disease. Revisión de los triatominae (Hemiptera, Reduviidae) y su significado como vectores del mal de Chagas. Bull Am Mus Nat Hist. 1979;163:123-520.

3. Hashimoto K, Schofield CJ. Elimination of Rhodnius prolixus in Central America. Parasit Vectors. 2012;5:45.

4. Oliveira MF, Silva JR, Dansa-Petretski M, de Souza W, Braga C, Masuda H, et al. Haemozoin formation in the midgut of the blood-sucking insect Rhodnius prolixus. FEBS Lett. 2000:477:95-8.

5. Paes MC, Oliveira MB, Oliveira PL. Hydrogen peroxide detoxification in the midgut of the blood-sucking insect, Rhodnius prolixus. Arch Insect Biochem Physiol. 2001;48:63-71.

6. Maddrell S. Excretion in the blood-sucking bug, Rhodnius prolixus Stål. I: The control of diuresis. J Exp Biol. 1963;40:247-56.

7. Maddrell S, Herman W, Mooney R, Overton J. 5-Hydroxytryptamine: a second diuretic hormone in Rhodnius prolixus. J Exp Biol. 1991;156:557-66.

8. Te Brugge V, Paluzzi J-P, Schooley DA, Orchard I. Identification of the elusive peptidergic diuretic hormone in the blood-feeding bug Rhodnius prolixus: a CRF-related peptide. J Exp Biol. 2011;214:371-81.

9. Paluzzi J-PV, Young P, Defferrari MS, Orchard I, Carlini CR, O'Donnell MJ. Investigation of the potential involvement of eicosanoid metabolites in anti-diuretic hormone signaling in Rhodnius prolixus. Peptides. 2012;34:127-34

10. Paluzzi J-P, Yeung C, O'Donnell MJ. Investigations of the signaling cascade involved in diuretic hormone stimulation of Malpighian tubule fluid secretion in Rhodnius prolixus. J Insect Physiol. 2013;59:1179-85.

11. Gonzalez R, Orchard I. Characterization of neuropeptide F-like immunoreactivity in the blood-feeding hemipteran, Rhodnius prolixus. Peptides. 2008;29:545-58.

12. Sevala VL, Sevala VM, Davey KG, Loughton BG. A FMRFamide-like peptide is associated with the myotropic ovulation hormone in Rhodnius prolixus. Arch Insect Biochem Physiol. 1992;20:193-203.

13. Ons S, Sterkel M, Diambra L, Urlaub H, Rivera-Pomar R. Neuropeptide precursor gene discovery in the Chagas disease vector Rhodnius prolixus. Insect Mol Biol. 2011;20:29-44.

14. Ons S, Richter F, Urlaub H, Pomar RR. The neuropeptidome of Rhodnius prolixus brain. Proteomics. 2009;9:788-92.

15. Lazzari CR. Orientation towards hosts in haematophagous Insects: an integrative perspective. In: Advances in Insect Physiology, Vol 37. San Diego: Elsevier Academic Press Inc; 2009. p. 1-+. Advances in Insect Physiology.

16. Guerenstein PG, Lazzari CR. Host-seeking: How triatomines acquire and make use of information to find blood. Acta Trop. 2009;110:148-58.

17. Manrique G, Lorenzo MG. The sexual behaviour of Chagas' disease vectors: chemical signals mediating communication between male and female Triatomine bugs. Psyche J Entomol. 2012;2012:1-8.

18. Latorre-Estivalis JM, Lazzari CR, Guarneri AA, Mota T, Omondi BA, Lorenzo MG. Genetic basis of triatomine behaviour: lessons from available insect genomes. Mem Inst Oswaldo Cruz. 2013;108:63-73.

19. Ponton F, Chapuis MP, Pernice M, Sword GA, Simpson SJ. Evaluation of potential reference genes for reverse transcription-qPCR studies of physiological responses in Drosophila melanogaster. J Insect Physiol. 2011;57:840-50.

20. Nolan T, Hands R, Bustin S. Quantification of mRNA using real-time RT-PCR. Nat Protoc. 2006;1:1559-82.

21. Vandesompele J, De Preter K, Pattyn F, Poppe B, Van Roy N, De Paepe A, et al. Accurate normalization of real-time quantitative RT-PCR data by geometric averaging of multiple internal control genes. Genome Biol Evol. 2002;3:1-12.

22. Shen G-M, Jiang H-B, Wang X-N, Wang J-J. Evaluation of endogenous references for gene expression profiling in different tissues of the oriental fruit fly Bactrocera dorsalis (Diptera: Tephritidae). BMC Mol Biol. 2010;11:76.

23. Biessmann $H$, Andronopoulou E, Biessmann MR, Douris V, Dimitratos SD, Eliopoulos $E_{1}$ et al. The Anopheles gambiae odorant binding protein 1 (AgamOBP1) mediates indole recognition in the antennae of female mosquitoes. PLoS One. 2010;5, e9471.
24. Li K-M, Ren L-Y, Zhang Y-J, Wu K-M, Guo Y-Y. Knockdown of Microplitis mediator odorant receptor involved in the sensitive detection of two chemicals. J Chem Ecol. 2012;38:287-94.

25. Dong X, Zhong G, Hu M, Yi X, Zhao H, Wang H. Molecular cloning and functional identification of an insect odorant receptor gene in Spodoptera litura (F.) for the botanical insecticide rhodojaponin III. J Insect Physiol. 2013;59:26-32.

26. Wang Z, Gerstein M, Snyder M. RNA-Seq: a revolutionary tool for transcriptomics. Nat Rev Genet. 2009;10:57-63.

27. Bonizzoni M, Dunn WA, Campbell CL, Olson KE, Dimon MT, Marinotti $\mathrm{O}$, et al. RNA-seq analyses of blood-induced changes in gene expression in the mosquito vector species, Aedes aegypti. BMC Genomics. 2011;12:82.

28. Nagalakshmi U, Wang Z, Waern K, Shou C, Raha D, Gerstein M, et al. The transcriptional landscape of the yeast genome defined by RNA sequencing. Science. 2008;320:1344-9.

29. Martin F, Riveron J, Alcorta E. Environmental temperature modulates olfactory reception in Drosophila melanogaster. J Insect Physiol. 2011:57:1631-42.

30. Radonić A, Thulke S, Mackay I, Landt O, Siegert W, Nitsche A. Guideline to reference gene selection for quantitative real-time PCR. Biochem Biophys Res Commun. 2004;313:856-62.

31. Huggett J, Dheda K, Bustin S, Zumla A. Real-time RT-PCR normalisation; strategies and considerations. Genes Immun. 2005;6:279-84.

32. Bustin S, Benes V, Garson J, Hellemans J, Huggett J, Kubista M, et al. The MIQE guidelines: minimum information for publication of quantitative real-time PCR experiments. Clin Chem. 2009;55:611-22.

33. Ling D, Salvaterra P. Robust RT-qPCR data normalization: validation and selection of internal reference genes during post-experimental data analysis. PLOS One. 2011;6:1-8.

34. Hornáková D, Matousková P, Kindl J, Valterová I, Pichová I. Selection of reference genes for real-time polymerase chain reaction analysis in tissues from Bombus terrestris and Bombus lucorum of different ages. Anal Biochem. 2010;397:118-20.

35. Pfaffl MW. A new mathematical model for relative quantification in real-time RT-PCR. Nucleic Acids Res. 2001;29, e45.

36. Pfaffl MW. Quantification strategies in real-time PCR. AZ of quantitative PCR. 2004;1:89-113.

37. Livak KJ, Schmittgen TD. Analysis of relative gene expression data using real-time quantitative PCR and the 2 (-Delta Delta C(T)) Method. Methods. 2001;25:402-8

38. Paim R, Pereira M, Di Ponzio R, Rodrigues J, Guarneri A, Gontijo N, et al. Validation of reference genes for expression analysis in the salivary gland and the intestine of Rhodnius prolixus (Hemiptera, Reduviidae) under different experimental conditions by quantitative real-time PCR. BMC Res Notes. 2012:5:128.

39. Selvey S, Thompson E, Matthaei K, Lea RA, Irving MG, Griffiths LR. $\beta$ Actin-an unsuitable internal control for RT-PCR. Mol Cell Probes. 2001;15:307-11.

40. Lee PD, Sladek R, Greenwood CM, Hudson TJ. Control genes and variability: absence of ubiquitous reference transcripts in diverse mammalian expression studies. Genome Res. 2002;12:292-7.

41. Ohl F, Jung M, Xu C, Stephan C, Rabien A, Burkhardt M, et al. Gene expression studies in prostate cancer tissue: which reference gene should be selected for normalization? J Mol Med. 2005;83:1014-24.

42. Czechowski T, Stitt M, Altmann T, Udvardi MK, Scheible W-R. Genome-wide identification and testing of superior reference genes for transcript normalization in Arabidopsis. Plant Physiol. 2005;139:5-17.

43. Suzuki T, Higgins $P$, Crawford D. Control selection for RNA quantitation. Biotechniques. 2000;29:332-7.

44. Thellin O, Zorzi W, Lakaye B, De Borman B, Coumans B, Hennen G, et al. Housekeeping genes as internal standards: use and limits. J Biotech. 1999;75:291-5

45. Paolacci AR, Tanzarella OA, Porceddu E, Ciaffi M. Identification and validation of reference genes for quantitative RT-PCR normalization in wheat. BMC Mol Biol. 2009;10:11.

46. Oliveira JG, Prados RZ, Guedes ACM, Ferreira PC, Kroon EG. The housekeeping gene glyceraldehyde-3-phosphate dehydrogenase is inappropriate as internal control in comparative studies between skin tissue and cultured skin fibroblasts using Northern blot analysis. Arch Dermatol Res. 1999;291:659-61. 
47. Majerowicz D, Alves-Bezerra M, Logullo R, Fonseca-de-Souza A, Meyer-Fernandes J, Braz G, et al. Looking for reference genes for real-time quantitative PCR experiments in Rhodnius prolixus (Hemiptera: Reduviidae). Insect Mol Biol. 2011;20:713-22.

48. Carey AF, Carlson JR. Insect olfaction from model systems to disease control. Proc Natl Acad Sci U S A. 2011;108:12987-95.

49. Hallem EA, Nicole Fox A, Zwiebel LJ, Carlson JR. Olfaction: mosquito receptor for human-sweat odorant. Nature. 2004;427:212-3.

50. Carey A, Wang G, Su C-Y, Zwiebel LJ, Carlson JR. Odorant reception in the malaria mosquito Anopheles gambiae. Nature. 2010;464:66-71.

51. Badsha F, Kain P, Prabhakar S, Sundaram S, Padinjat R, Rodrigues V, et al. Mutants in Drosophila TRPC channels reduce olfactory sensitivity to carbon dioxide. PLoS One. 2012;7:1-11.

52. Bohbot J, Vogt RG. Antennal expressed genes of the yellow fever mosquito (Aedes aegypti L.); characterization of odorant-binding protein 10 and takeout. Insect Biochem Mol Biol. 2005;35:961-79.

53. latrou K, Biessmann $\mathrm{H}$. Sex-biased expression of odorant receptors in antennae and palps of the African malaria vector Anopheles gambiae. Insect Biochem Mol Biol. 2008;38:268-74.

54. Vásquez G, Fischer P, Grozinger C, Gould F. Differential expression of odorant receptor genes involved in the sexual isolation of two Heliothis moths. Insect Mol Biol. 2011;20:115-24.

55. Patch HM, Velarde RA, Walden KK, Robertson HM. A candidate pheromone receptor and two odorant receptors of the hawkmoth Manduca sexta. Chem Senses. 2009;34:305-16.

56. Wanner KW, Nichols AS, Walden KK, Brockmann A, Luetje CW, Robertson HM. A honey bee odorant receptor for the queen substance 9-oxo-2-decenoic acid. Proc Natl Acad Sci U S A. 2007:104:14383-8.

57. Robertson H, Wanner K. The chemoreceptor superfamily in the honey bee, Apis mellifera: expansion of the odorant, but not gustatory, receptor family. Genome Res. 2006;16:1395-403.

58. Scharf ME, Zhou X, Schwinghammer MA. Application of RNA interference in functional genomics studies of a social insect. Methods Mol Biol. 2008;442:205-29.

59. Lord J, Hartzer K, Toutges M, Oppert B. Evaluation of quantitative PCR reference genes for gene expression studies in Tribolium castaneum after fungal challenge. J Microbiol Methods. 2010;80:219-21.

60. Bieke S, Dirk CG, Karen G, Marleen B, Luc JP, Frans JJ. Reference gene selection for insect expression studies using quantitative real-time PCR: the head of the honeybee, Apis mellifera, after a bacterial challenge. J Insect Sci. 2008:8:1-10.

61. Altschul SF, Madden TL, Schaffer AA, Zhang J, Zhang Z, Miller W, et al. Gapped BLAST and PSI-BLAST: a new generation of protein database search programs. Nucleic Acids Res. 1997;25:3389-402.

62. Rozen S, Skaletsky H. Primer3 on the WWW for general users and for biologist programmers. Methods Mol Biol. 2000;132:365-86.

63. Altschul SF, Gish W, Miller W, Myers EW, Lipman DJ. Basic local alignment search tool. J Mol Biol. 1990:215:403-10.

64. Staden R, Beal KF, Bonfield JK. The Staden package, 1998. Methods Mol Biol. 2000;132:115-30.

65. Andersen $\mathrm{CL}$, Jensen $\mathrm{J}$, Ørntoft TF. Normalization of real-time quantitative reverse transcription-PCR data: a model-based variance estimation approach to identify genes suited for normalization, applied to bladder and colon cancer data sets. Cancer Res. 2004;64:5245-50.

66. Turner C, Davy M, MacDiarmid R, Plummer K, Birch N, Newcomb R. RNA interference in the light brown apple moth, Epiphyas postvittana (Walker) induced by double-stranded RNA feeding. Insect Mol Biol. 2006;15:383-91.

67. Marioni JC, Mason CE, Mane SM, Stephens M, Gilad Y. RNA-seq: an assessment of technical reproducibility and comparison with gene expression arrays. Genome Res. 2008;18:1509-17.

68. Sinha DK, Smith CM. Selection of reference genes for expression analysis in Diuraphis noxia (Hemiptera: Aphididae) fed on resistant and susceptible wheat plants. Sci Rep. 2014;4:1-6.

\section{Submit your next manuscript to BioMed Central and take full advantage of:}

- Convenient online submission

- Thorough peer review

- No space constraints or color figure charges

- Immediate publication on acceptance

- Inclusion in PubMed, CAS, Scopus and Google Scholar

- Research which is freely available for redistribution 